\title{
Significant Outcome Of Biliary Anastomosis In Living Related Donor Liver Transplantation
}

\author{
Mohammed Hassan MD, Wael L. Tobar MD, Amr Aiad MD, Adel Hosny \\ MD, Mostafa El-Shazly MD,Ahamed Hussein,MSC \\ Department of General Surgery, Cairo University
}

\begin{abstract}
Variations in the anatomy of the intrahepatic bile ducts have long been recognized. Serious consideration of the surgical anatomy of the liver began, however, with the advent of minimally invasive therapeutic intervention for bile duct or hepatic resection, or partial liver transplantation. Thus, accurate knowledge of the anatomy of IHDs is critical. 30 cases were included in this study. Right lobe donation in 27 cases and left lobe donation in 3 cases. The main indication for transplantation was end stage liver disease: hepatitis $\mathrm{C}$ end stage liver cirrhosis in 29 cases, while hepatocellular carcinoma on top of liver cirrhosis was the remaining case. Pretransplantation preparation of both donors and recipients was done.No mortality was reported to either any of the donors or the recipients. Postoperative donor biliary complications occurred in 1 case and conservative treatment was followed with complete resolution of the condition .Postoperative recipient biliary complicatioins occurred in eleven cases in the form of biloma, biliary leakage, biliary stricture, cholangitis and peritonitis, six of them with two ducts anastomosis. They were managed and cured without residual pathology.
\end{abstract}

\section{Introduction}

Living donor liver transplantation (LDLT) has become an acceptable alternative for adults in need of orthotopic liver transplantation (OLT) who are not likely to receive a deceased donor (cadaveric) organ in a timely fashion. The need for LDLT has arisen because of a persistent shortage of adult deceased donor livers (Schroeder et al.,2005).

In hepatic resection for living donor liver transplantation (LDLT), an accurate knowledge of the anatomy of intrahepatic bile ducts (IHDs) is thus critical if the liver is to be successfully harvested and postoperative complications minimized (Ching and Sheung, 2006).

The normal biliary anatomy is thought to be present in $58 \%$ of the population. Biliary anomalies are common and may lead to exclusion of many donors and it also affect the outcome for both donors and recipients. Evaluation of the donor liver is expensive and often leads to the exclusion of potential donors( Ramacciato et al. , 2006).

\section{Patients \& Methods}

Thirty (30) cases were included in this study. RT. Lobe donation 27, LT. Lobe donation 3, range of age 25-45 mean age 30 , indications for transplantation are End stage liver disease: $\mathrm{HCV}$ related liver cirrhosis in 29 cases, Hepatocellular carcinoma on top of liver cirrhosis and HCV in 1 patient. This patient had no extrahepatic spread or portal vein thrombosis. 3 steps evaluation of both donor \& recipient. Donor (step 1) Liver functions: total bilirubin, direct bilirubin, ALT, AST, total proteins, serum albumin, alkaline phosphatase, GGT, Kidney functions: blood urea, creatinine, uric acid, $\mathrm{Na}, \mathrm{K}$, Urine, Stools analysis, Blood Grouping , CBC \& ESR. PT, PC \& INR, PTT. HCV Ab. HBsAg \& HbcAb total, Abdominal and pelvic ultrasonography vascular hepatic Doppler, CT volumetry. Donor (step 2) Bleeding time, clotting time, TT, Fibrinogen , ATIII, Protein C, Protein S, Factor $\mathrm{V}, \mathrm{ASO}, \mathrm{CRP}, \mathrm{VDRL}, \mathrm{LDH}$, 
Cholesterol, TG, FBS, PPS, Amylase, Lipase, Ca, Copper, Fe, TIBC ,Tumors markers : CA19.9, CA 125, Alpha fetoprotein , CEA ,HAV IgM / HAV total / HBsAb / HBeAb / HBeAg / HBcIgM / EBV IgM / EBV IgG / CMV IgG / CMV IgM / HIV I,II, Chest $\mathrm{X}$ ray,CT chest ,MRCP Echocardiography, ECG, pulmonary function tests. Donor (step 3) Liver biopsy and Psychiatric consultation. Recipient (step 1) as donor without CT volumetry. Recipient (step 2) Bleeding time, clotting time,, TT, Fibrinogen, ATIII, Protein C, Protein S, Factor V, ASO, CRP, VDRL, LDH, Cholesterol, TG, FBS, PPS, Amylase, Lipase, $\mathrm{Ca}$, Copper, Fe, TIBC, Tumors markers : CA19.9, CA 125, Alpha fetoprotein , CEA, Viral profile: HAV IgM / HAV total / HBsAb / HBeAb / HBeAg / $\mathrm{HBcIgM} / \mathrm{EBV}$ IgM / EBV IgG / CMV IgG / CMV IgM / HIV I,II, rubella IgG, HCV PCR(Qualitative). Herpes 1 IgG,Herpes II IgG, Chest $X$ ray, spiral abdominal CT with contrast, Arterial \& venous duplex for both lower limbs, ECG, Echocardiography, Thallium scan, Upper G.I endoscope and Pulmonary function tests. Recipient (step 3) Nephrology, cardiology, ophthalmology, Dental, psychiatric, chest and ENT consultations.

All living donors had intraoperative cholangiography to confirm the information gained about their biliary anatomy by the MRCP before cutting the graft, thus help in knowing the number of the bile ducts in the graft that will be anastomosed to the recipient biliary system. The recipient surgery consisted of a total hepatectomy with preservation of the IVC. If multiple accessory hepatic veins were preserved, a common cuff was constructed from the individual veins at the back table when technically possible. The donor right hepatic vein was anastomosed to the orifice of the recipient right hepatic vein. Double right hepatic veins were joined in a common trunk and anastomosed to the orifice of the recipient right hepatic vein as well. If the diameter of the orifice of the recipient right hepatic-vein was inadequate, it was enlarged by creating a slit. Accessory veins were anastomosed directly to the IVC in an end-to-side fashion while the cava was still clamped. The donor right portal branch was anastomosed to the recipient main portal branch unless, because of significant size mismatch, the right portal branch was more appropriate. Double donor portal venous branches were joined to form a common trunk and anastomosed to the recipient main portal vein. Arterial anastomosis was performed using microvascular technique using interrupted $8 / 0$ prolene suture. Anastomoses were constructed between the donor right hepatic artery and the recipient right hepatic artery. The bile ducts were individually drained through duct to duct anastomosis using 6/0 polydioxanone sutures(PDS), the posterior layer is sutured continuously while the anterior layer is sutured by interrupted sutures. Biliary tubes were used in some cases with very small bile ducts.

\section{Results}

The branching patterns of IHDs were classified as one of seven types. (Type 1) is typical, i.e. a common hepatic duct is formed by fusion of the RHD and LHD (Fig. 1). The RHD arises through fusion of the RASD, which drains anterior segments $\mathrm{V}$ and VIII, and the RPSD, which drains posterior segments VI and VII. (Type 2) involves triple confluence, the simultaneous emptying of the RASD, RPSD and LHD into the common hepatic duct (CHD) (Fig. 2). (Type 3), representing anomalous drainage of the RPSD, is subdivided into 3 types $3 \mathrm{~A}, 3 \mathrm{~B}$, and $3 \mathrm{C}$, according to the drainage pattern of the RPSD. In type 3A, this drains into the LHD (Fig. 3a); in type 3B, into the CHD (Fig. 3b); and in type 3C, into the cystic duct. (Type 4) IHD systems are those in which the RHD drains into the cystic duct (Fig. 4). (Type 5), in which an accessory duct is present, is subdivided into types $5 \mathrm{~A}$ and $5 \mathrm{~b}$ according to the drainage pattern of duct: in type 5A, it drains into the CHD (Fig. 5a), and in type 5B, into the RHD (Fig. 5b). (Type 6) is one in which segments II and III of the segmental duct drain individually into the RHD or CHD (Fig. 6), while a type 7 shows unclassified or complex variation (Fig.7). The frequencies of each type were as the follows: type 1, 63\% ( $\mathrm{n}=188)$; type $2,10 \%$ $(n=29)$; type 3A, $11 \%(n=34)$; type 3B, 6\% $(\mathrm{n}=19)$; type 3C, $2 \%(\mathrm{n}=6)$, type $4,0 \%$ $(\mathrm{n}=1)$; type $5 \mathrm{~A}, 3 \%(\mathrm{n}=8)$; type $5 \mathrm{~B}, 3 \%$ 


\section{Mohammed Hassan MD et al}

$(\mathrm{n}=8)$; type $6,1 \% \quad(\mathrm{n}=4)$; type $7,1 \%$ $(n=3)$. In eight type-5A cases, the accessory duct was combined with either type 1 $(n=3)$, type $2(n=3)$ or type $3 A(n=2)$, and in eight type-5B cases, with either type 1 $(\mathrm{n}=6)$ or type $3 \mathrm{~A}(\mathrm{n}=2)($ Park et al., $1991 ;$ jin et al., 2003).

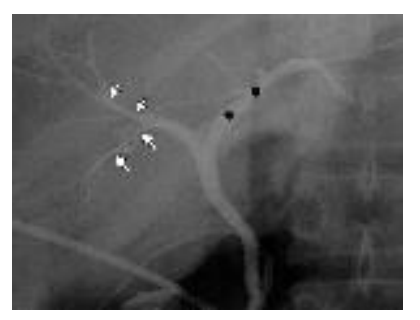

Fig. 1. Typical IHD anatomy (type 1). Operative cholangiogram shows that the CHD is formed by fusion of the RHD and LHD (asterisks). The RHD is formed by fusion of the RASD (small arrows), which drains anterior segments $\mathrm{V}$ and VIII, and the RPSD (large arrows), which drains posterior segments VI and VII.

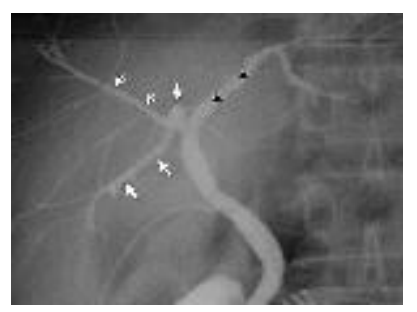

Fig. 2. Triple confluence (type 2). Operative cholangiogram demonstrates simultaneous emptying of the RASD (small arrows), RPSD (large arrows) and LHD (asterisks) into the CHD.
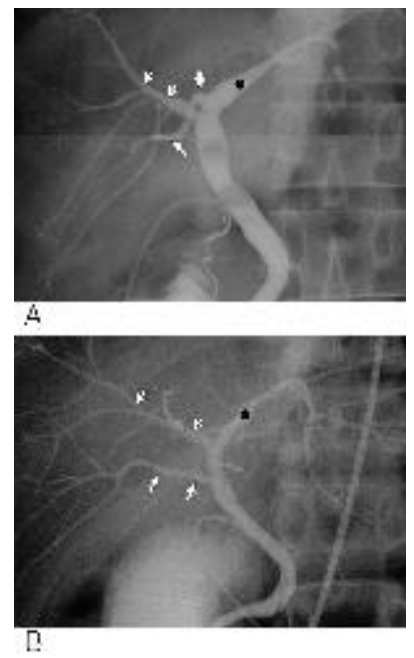

Fig. 3. Anomalous drainage of the RPSD (type 3). A. Drainage of the RPSD into the LHD (type 3A). B. Drainage of the RPSD into the CHD (type 3B). Each operative cholangiogram depicts drainage of the RPSD (large arrows) into the LHD (asterisk) and CHD, respectively. Small arrows $=$ RASD

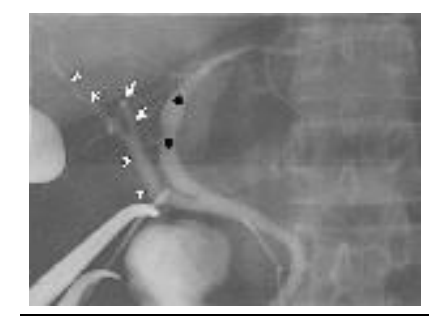

Fig. 4. Drainage of the RHD into the cystic duct (type 4). Operative cholangiogram shows the RHD (arrowheads), formed by fusion of the RASD (small arrows) and RPSD (large arrows), into the cystic duct. Asterisks $=$ LHD

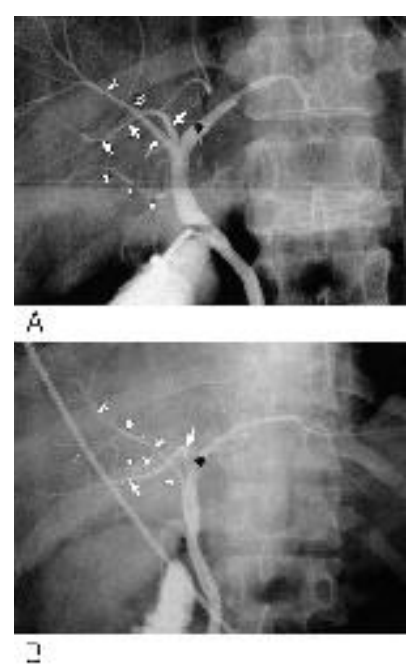

Fig. 5. Accessory hepatic ducts (type 5). A. Drainage of an accessory hepatic duct into the CHD (type 5A). B. Drainage of an accessory hepatic duct into the RHD. Operative cholangiograms indicate that accessory hepatic ducts (arrowheads) drain into the CHD and RHD, respectively. Small arrows $=$ RASD, large arrows $=$ RPSD 


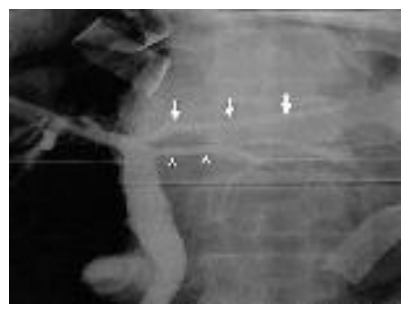

Fig. 6. Segments II and III of the segmental duct drain individually into the RHD or CHD (type 6). Operative cholangiogram shows that segmental duct branches S2 (large arrows) and S3 (arrowheads) drain into the CHD. There is no left main duct.

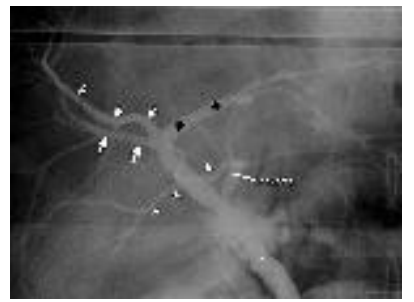

Fig. 7. Unclassified or complex variation (type 7). Cholangiogram shows type-3 trifurcation, with the accessory right posterior segmental duct (arrowheads) pouring into the caudate branch of the bile duct. Large arrows=RPSD, small arrows $=$ RASD, asterisks $=\mathbf{L H D}$.

All living donors underwent magnetic resonance cholangiopancreatography (MRCP) for preoperative assessment of their biliary anatomy. MRCP gave information about the number of the right and left bile ducts. 


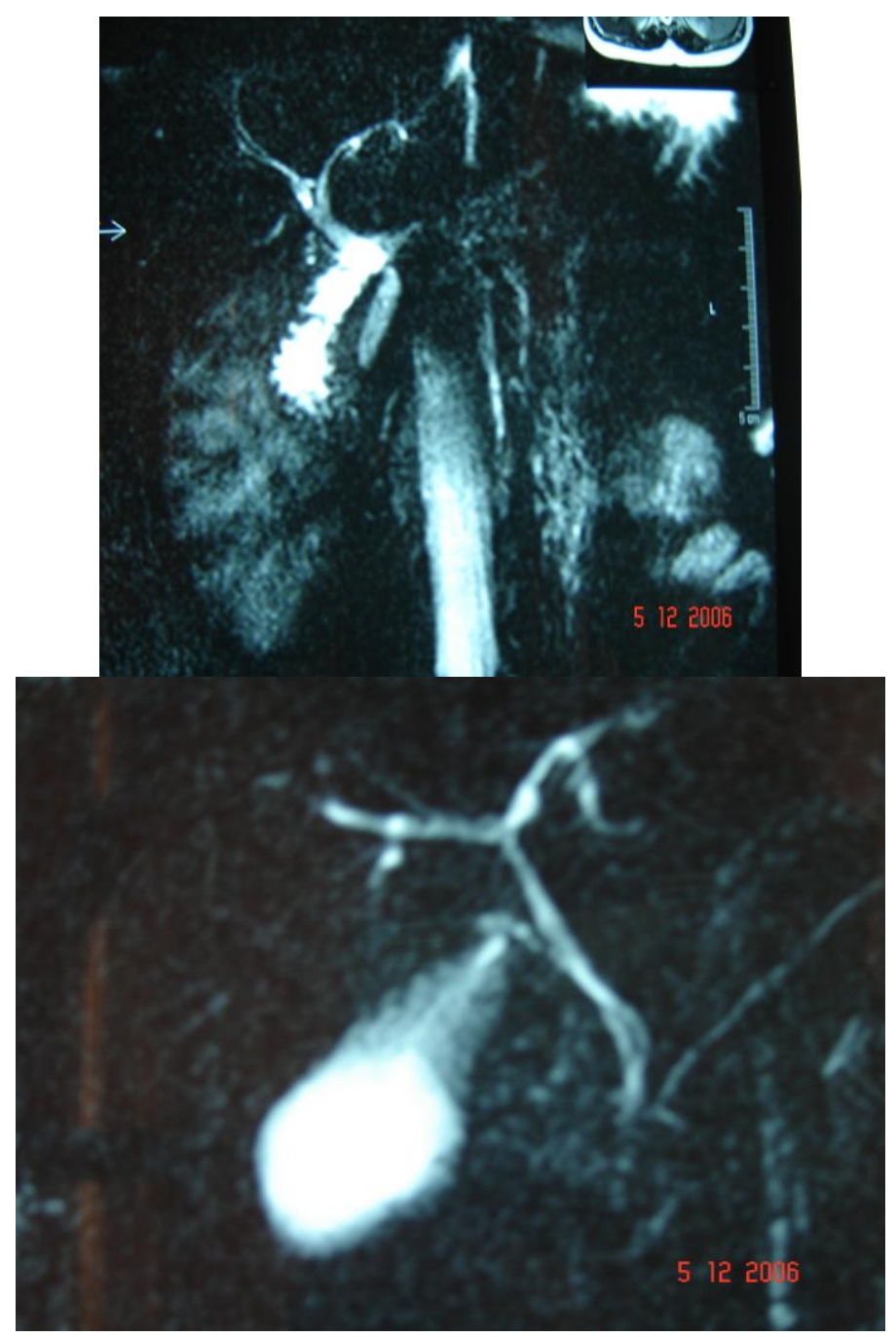

Fig(7): MRCP done for the donor showing single right bile duct and single left bile duct.

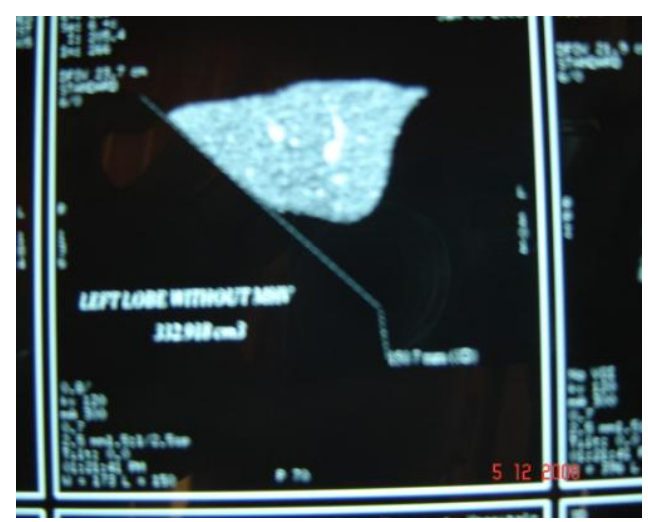

Fig (8) CT volumetry done to the donor to calculate the size of the graft and the remaining part of the liver. 
Biliary anastomosis is done to the recipient using 6/0 PDS sutures, ductoplasty was done for 4 right lobe grafts where 2 bile duct openings are transformed into single duct opening before performing the biliary anastomosis in the recipient, biliary tubes were applied in 3 cases only.

\begin{tabular}{|c|c|c|c|c|c|c|c|}
\hline $\begin{array}{c}\text { Numb } \\
\text { er of } \\
\text { donors }\end{array}$ & $\begin{array}{c}\text { Number of } \\
\text { right lobe } \\
\text { donation }\end{array}$ & $\begin{array}{c}\text { Number of } \\
\text { left lobe } \\
\text { donation }\end{array}$ & $\begin{array}{c}\text { Grafts } \\
\text { with } \\
\text { single } \\
\text { bile } \\
\text { duct }\end{array}$ & $\begin{array}{c}\text { Grafts } \\
\text { with } 2 \\
\text { bile } \\
\text { ducts }\end{array}$ & $\begin{array}{c}\text { Cases that had } \\
\text { ductoplasty }\end{array}$ & $\begin{array}{c}\text { Donors with } \\
\text { postoperative } \\
\text { biliary } \\
\text { complications }\end{array}$ & $\begin{array}{c}\text { Recipients with } \\
\text { postoperative } \\
\text { biliary } \\
\text { complications }\end{array}$ \\
\hline 30 & 27 & 3 & 17 & 13 & 4 & 1 & 11 \\
\hline
\end{tabular}

Only one donor developed postoperative biliary leakage and subphrenic collection. ERCP was done with stenting of the common bile duct and placing pig tail in the subphrenic collection for its drainage.
The condition totally resolved. This case donated part of his right lobe with 2 bile ducts. 11 recipients developed post operative biliary complications

\begin{tabular}{|c|c|c|c|c|c|c|}
\hline $\begin{array}{c}\text { Recipient that had } \\
\text { postoperative biliary } \\
\text { complication }\end{array}$ & Biloma & $\begin{array}{c}\text { Post } \\
\text { operative } \\
\text { Jaundice }\end{array}$ & $\begin{array}{c}\text { Biliary } \\
\text { leakage }\end{array}$ & $\begin{array}{c}\text { Biliary } \\
\text { stricture }\end{array}$ & Cholangitis \\
\hline 11 & 1 & 2 & 2 & 4 & 1 \\
\hline
\end{tabular}

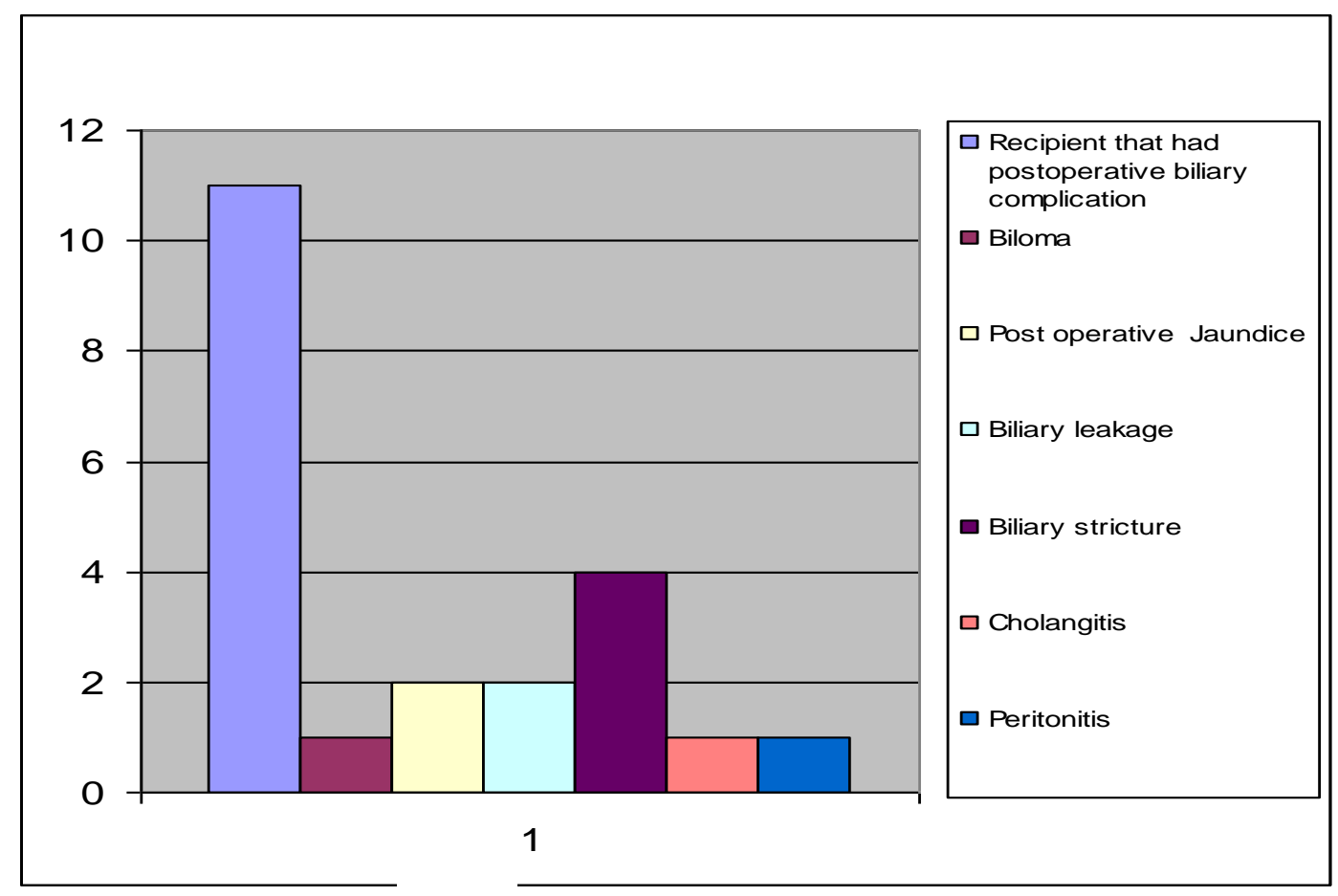

Diagram (1) : Representing post operative biliary complication of the recipient. 


\section{Mohammed Hassan MD et al}

Thirteen (13) recipients had 2 bile duct anastomosis of them 4 had ductoplasty, 6 of them $(46.1 \%)$ had postoperative biliary complications $(54.5 \%)$ of total 11 recipient with biliary complications. 1 patient developed epigastric biloma $250 \mathrm{cc}$., Ultrasound guided aspiration was done with complete resolution of the condition. This patient was a recipient of right lobe graft with 2 bile ducts.

Two (2) patients developed slight elevation of the serum bilirubin one week after the operation. Conservative treatment was followed as it was attributed to oedema of the biliary tree. Complete resolution occurred with return of the liver functions to its normal level. These 2 patients were recipients of right lobe grafts with 2 bile ducts.

Tow (2) patients developed post operative biliary leakage detected by persistent increase in the amount of bile in the drains. ERCP was done with application of stent in the common bile duct. Control of leakage occurred with complete resolution of the condition. Theses 2 patients were recipients of right lobe grafts one had single bile duct while the other had 2 bile ducts.

One patient developed post operative jaundice with elevation of the serum bilirubin (day14). Percutaneous transhepatic drainage (PTD )was done with adequate drainage. During the course of follow up ( 6 months later), ERCP was done and revealed stricture proximal to the site of anastomosis. Balloon dilatation and insertion of a stent in the common bile duct was done with adequate drainage and complete resolution of the condition. This patient was a recipient of right lobe graft with 2 bile ducts.

Two (2) patients developed post operative jaundice with elevation of the serum bilirubin. ERCP and PTD with external and internal stenting were done. Adequate drainage was obtained with resolution of the condition. During the course of follow up ( after 5 months), the patient developed obstructive jaundice with elevation of the serum bilirubin. ERCP failed and hepatico-jujenostomy Roux En Y was done with complete resolution of the condition and return of the liver functions to its normal level. These 2 patients were recipient of right lobe graft one had single bile duct while the other had 2 bile ducts.

One patient developed cholangitis after being discharged from the hospital (1 month post operative).Abdominal ultrasound was done and revealed multiple liver abscesses. ERCP was done but failed. Percutaneous transhepatic drainage (PTD) was done with external and internal drainage under cover of antibiotics. Resolution of the condition occurred with return of the liver functions to its normal level. Abdominal ultrasound was done in the follow up course and 2 residual liver abscesses were detected. This patient was a recipient of right lobe graft with single bile duct.

One patient developed post operative jaundice with elevation of the serum bilirubin. ERCP was done 4 weeks after the operation and revealed biliary stricture. A stent was inserted in the common bile duct with adequate biliary drainage and complete resolution of the condition. This patient was a recipient of a left lobe graft with single bile duct.

One patient presented to the emergency department after being discharged from the hospital ( 6 weeks post operative) with picture of peritonitis. Exploration was done and revealed biliary leakage. Peritoneal lavage was done. ERCP was done with insertion of a stent in the common bile duct. However, the jaundice persisted for 2 weeks. MRCP was done and revealed stricture above the stent in the common bile duct. ERCP was done with insertion of the suitable stent. Leakage stopped with complete resolution of the condition. This patient was a recipient of right lobe graft with single bile duct. 


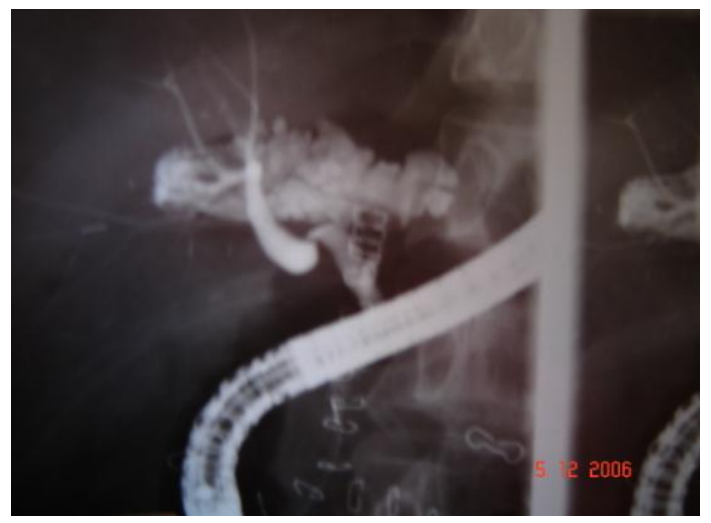

Fig (9): ERCP done to one of the recipients showing stricture at the site of biliary anastomosis and leakage from the cut surface.

\section{Discussion}

Variations in the anatomy of the intrahepatic bile ducts have long been recognized. Serious consideration of the surgical anatomy of the liver began, however, with the advent of minimally invasive therapeutic intervention for bile duct or hepatic resection, or partial liver transplantation. Thus, accurate knowledge of the anatomy of IHDs is critical, anatomic variants of IHDs can be detected at ERCP or MRCP ( Gulliver et al.,1991; Gazelle et al.,1994; Huang et al.,1996; Mortele and Ross, 2001) .

In adult LDLT, donor safety is of paramount importance, and ideally, there should not be any donor deaths. However, it is unrealistic to expect zero mortality with major hepatic resection even in healthiest subjects. The worldwide estimated mortality ranges between $(0.2 \%$ to $0.5 \%)$ as reported by Cary \& Paul 2003. The mortality rate in our series is zero percent.

The extension of LDLT from children to adults went ni parallel with the shift from using the left graft to the right, and there are no large adult LDLT studies comparing the differences in donor complications with right vs left lobe resection (Lin et al ., 2006). Right graft LDLT in our series was 27 cases and only 3 cases underwent left graft LDLT. Comparing the differences in overall complications in right graft vs left graft LDLT in our series is statistically insignificant because of the small number of cases (Mellena et al.,2004).

As the frequency of LDLT rises so do the associated complications and, consequently, the need for accurate rapid diagnosis. Biliary complications, especially anastomotic leak and stricture are an important and common cause of morbidity and graft failure. Frequencies vary among centres, with recent large cohorts ranging from $11 \%$ to $30 \%$ and reported ranges overall of $9 \%$ to $50 \%{ }^{10}$. In our series the overall ratio of biliary complications was $(36.6 \%)$ which is an accepted ratio worldwide.

Ultrasound is sensitive initial mean of diagnosing biliary complications in LDLT and can be employed to guide aspiration of some of these complications as biloma and guide drainage of perihepatic collections and abscesses formation. In our series ultrasound is used routinely postoperatively for early detection and management of biliary complications.

Duct to duct anastomosis was performed to all our cases because it is the procedure of choice in biliary anastomosis and having advantages over bilio-enteric anastomosis as reported by Ching \& Sheung 2006. We used 6/0 polydioxanon (PDS) sutures and not $6 / 0$ prolene to achieve sound and healthy biliary anastomosis which has been referred to as the achilis tendon of LDLT surgery.

Adjoining of 2 right hepatic duct orifices(ductoplasty) to form a single orifice without creating a tension -free septum was done in 4 cases in our series to have sound duct to duct anstomosis to preserve 
adequate blood supply to right hepatic duct with no post transplant biliary complication.

Biliary reconstruction is one of the most challenging parts of the right lobe LDLT and biliary complications have been reported as the first source of surgical complications of this procedure.In our series, we had single donor biliary complication ( $3.3 \%$ ) which is matching with the results of Ramacciato et al., 2006. This patient had biliary leakage, he responded well to conservative treatment and ERCP stenting was removed after improvement of the condition of the patient.

The post transplant biliary complications of the recipients in our series occurred in 11 patients, with ratio of $36.6 \%$ which matches with Bijan et al. (2005) who had a ratio of $36.5 \%$.

The 2 patients, who developed slight elevation of the bilirubin level, responded well to conservative treatment and follow up with complete recovery after couple of weeks.It was attributed to oedema at the site of biliary anastomosis. This conservative management matches with Lin et al., 2006.

One patient developed biloma, which was diagnosed by the routine ultrasound. Ultrasound guided aspiration was done with complete recovery.This line of treatment matches with that of Yazumi \& Chiba 2005.

The 2 patients who developed biliary leakage were treated by ERCP and insertion of biliary stent with complete recovery.This lineof treatment matches with that of Shah et al. (2004) who successfully treated such complications prior to attempt more invasive interventions.

One patient developed post transplant jaundice with marked elevation of the serum bilirubin due to stricture proximal to the biliary anastomosis. Drainage procedure and balloon dilatation with stent insertion was done with complete recovery of the patient. This protocole of management matches with Alazmi et al.(2006).

One patient developed cholangitis after hospital discharge, was diagnosed by ultrasound to have multiple liver abscesses. The patient responded to drainage procedure and antibiotics. This line of management matches with that used by
Shah et al., 2004.

The 2 patients who developed recurrent post transplant jaundice with failure of ERCP and stenting were managed surgically by performing hepaticojujenostomy Roux -en-Y with recovery of the patients. This line of management goes with that followed by Shah et al., 2004.

One patient developed peritonitis after hospital discharge proved to be due to biliary leakage. The case was managed by peritoneal lavage and ERCP with stenting. The condition resolved totally. This line of treatment goes with that used by Alazmi et al., 2006.

\section{References}

1. Alazmi WM, Fogel EL, Watkins JL, McHenry L, Tector JA, Fridell J, Mosler P, Sherman S, Lehman GA (2006): Recurrence rate of anastomotic biliary strictures in patients who have had previous successful endoscopic therapy for anastomotic narrowing after orthotopc liver transplantation. Endoscopy., 38 (6) : 571 - 574.

2. Bijan E, Zakiyah K, John F (2005): Technical consideration in liver transplan-tation:what hepatologist needs to know (and every surgeon should practice). Liver transplantation ., 11 (8): 861-871.

3. Cary H \& Paul P J (2003): Adult living donor liver transplantation.Medscape general medicine; 5(3) 891-895

4. Gazelle GS, Lee MJ, Mueller PR.(1994): Cholangiographic segmental anatomy of the liver. RadioGraphics; 14:1005-1013

5. Gulliver DJ, Cotton PB, Baillie J.(1991): Anatomic variants and artifacts in ERCP interpretation. AJR. Am. J. Roentgenol., 156:975980

6. Huang TL, Cheng YF, Chen CL, Chen TY, Lee TY.(1996): Variants of the bile ducts: clinical application in the potential donor of livingrelated hepatic transpla-ntation. Transplant .Proc., 28:1669-1670

7. Jin W C, Tae K K, Kyoung W K. Ah Y K Pyo NK,Hyun K H, Moon G L(2006): Anatomic Variation in Intrahepatic Bile Ducts: an Analysis of Intraoperative Cholangiograms in 
300 Consecutive Donors for Living Donor Liver Transplantation. Korean Journal of Radiology., 4(2):8590

8. Lin CH, Chen TW, Chou SJ, Hsieh H.F, Chu HC, Yu JC, Liu YC, Hsieh CB ( 2006): Biliary complications after liver transplantation.;22 (2): 567-571

9. Mellena $\mathbf{D} \mathbf{B}$, Gerald $\mathbf{R} \mathbf{M}$ and Denise M H (2004): Diagnosing biliary complic-ations of orthotopic liver transplantation with mangafodipir trisodium- enhanced MR cholangiography: comparison with conventional MR choalangiography. AJR ., 182:14971504.

10. Mortele KJ and Ros PR (2001): Anatomic variants of the biliary tree: MR cholangiographic findings and clinical applications. AJR. Am. J. Roentgenol., 177:389-394

11. Park CH, Cho HJ, Kwack EY, Choi CS, Kang IW, Yoon JS. (1991) :Intrahepatic biliary duct anatomy and its variations. J. Korean Radiol. Soc., 27:827-831.

12. Ramacciato G, Varotti G, Quintini C, Masetti M, Benedetto D F, Grazi GL, Ercolani G,
Cescon M, Ravaioli M, Lauro A P (2006): Impact of biliary complications in right lobe living donor liver transplantation. Transpl. Int., 19 (2): 122-7.

13. Schroeder T, Malago M, Debatin JF.(2005): "All-in-one" imaging protocols for the evaluation of potential living liver donors: comparison of magnetic resonance imaging and multidetector computed tomography.

Liver Transpl.,11(7):776-87.

14. Ching $\mathbf{S} \mathbf{C}$ and Sheung $\mathbf{T} \mathbf{F}$ (2006):Right liver adult-to-adult live donor liver transplantation in Hong Kong. Transplantation Reviews, 20 (1): 34-40.

15. Shah JN, Ahmad NA, Shetty K, Kochman ML, Long WB, Brensinger CM, Pfau PR, Olthoff K, Markmann J Shaked A, Reddy KR, Ginsberg GG (2004): Endoscopic management of biliary complications after adult living donor liver transplantation. Am. J. Gastroenterol., 99 (7): 1291-5

16. Yazumi $S$ \& Chiba $T$ (2005): Biliary complications after a right lobe living donor transplantation. J. Gastroenterol., 40 (9): 861-865. 


\section{نتائج توصيل القتوات المرارية فى المتبرع الحي ذو القرابة فى زراعة الكبا وتأثيرها على النتائج النيج}

محمد حسن، وائل طوبار، عمرو عياد، عادل حسني، مصطفى الثاذلى, أحمد حسين عين عاد

قسم الجر احة العامة - جامعة القاهرة

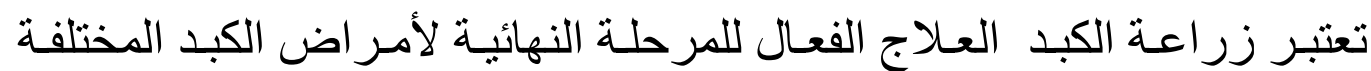

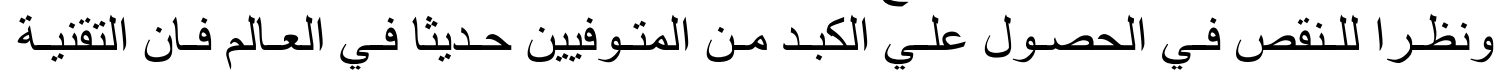

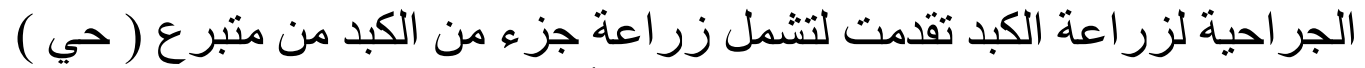

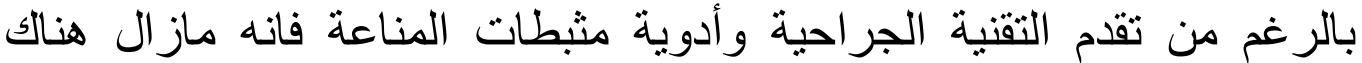

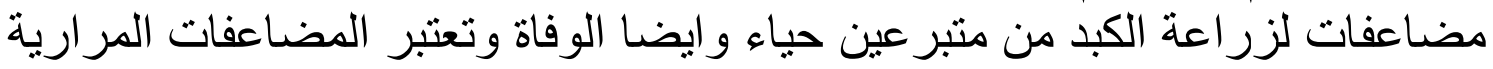

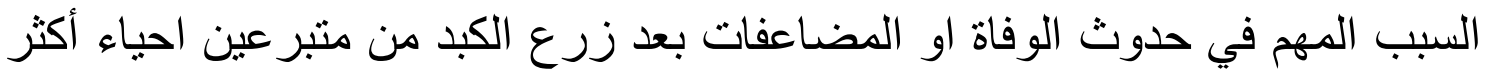

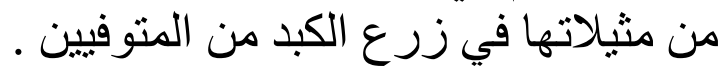

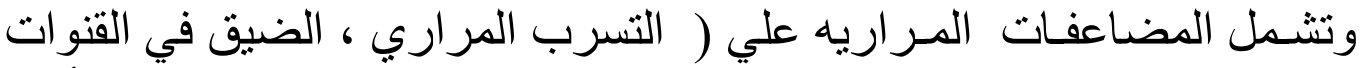

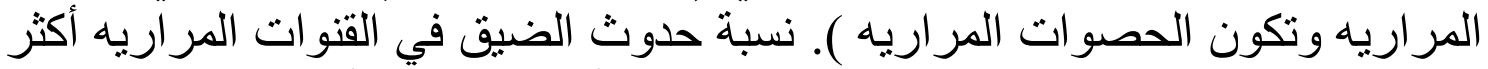

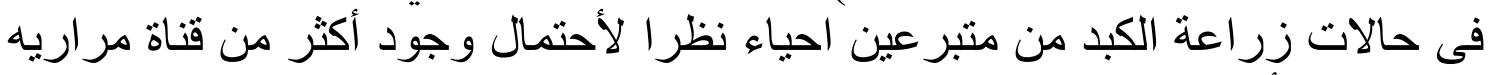

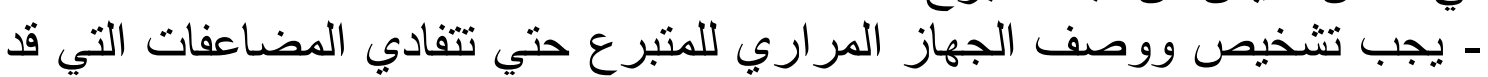

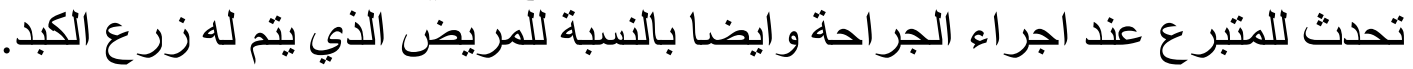

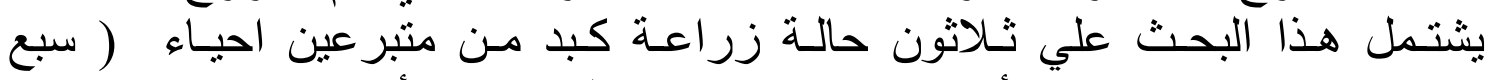

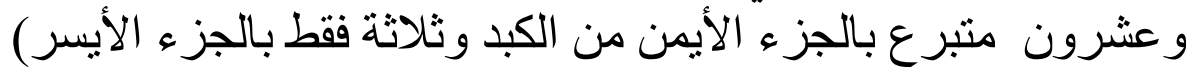

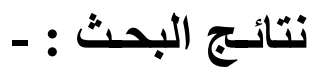
المضاعفات المـراريه للمتبرعين الأحياء حدثت في حالـة واحدة ( التسرب

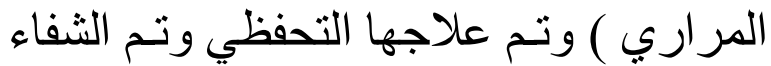

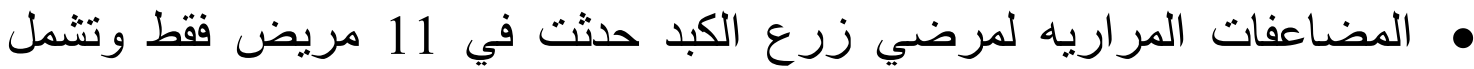

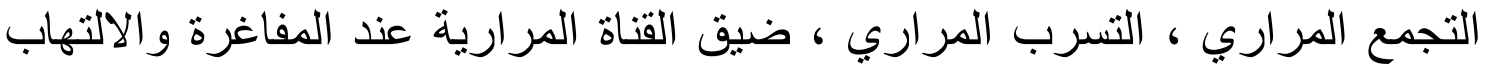

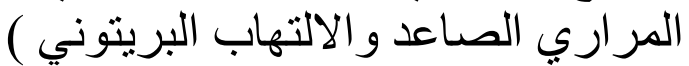
ثم علاج جميع المضاعفات بصورة مرضيه الأبهابه ولم تحدث أى حسالة وفـاة 